\title{
2669. Dynamic behavior of reinforced concrete panels subjected to blast loading
}

\author{
Jong Yil Park ${ }^{1}$, Min Sook Kim², Young Hak Lee ${ }^{3}$ \\ ${ }^{1}$ Department of Safety Engineering, Seoul National University of Science and Technology, \\ 232 Gongneung-ro, Seoul, Korea \\ ${ }^{2,3}$ Department of Architectural Engineering, Kyung Hee University, 1732 Deogyeong-daero, \\ Yongin, Korea \\ ${ }^{3}$ Corresponding author \\ E-mail:1jip111@seoultech.ac.kr,kimminsook@khu.ac.kr,3leeyh@khu.ac.kr
}

Received 16 May 2017; received in revised form 20 July 2017; accepted 1 August 2017 DOI https://doi.org/10.21595/jve.2017.18931

Check for updates

\begin{abstract}
This paper presents experimental and analytical results for dynamic response of reinforced concrete one-way slab under blast loading. Steel frame with massive concrete foundation to minimize rigid movement was prepared for fixed-fixed boundary condition. Two $1500 \times 2350 \times 150 \mathrm{~mm}$ RC slabs were tested under surface bursts of $50 \mathrm{~kg}$ TNT and $100 \mathrm{~kg}$ TNT at standoff distance of $20 \mathrm{~m}$. Types of measured data related to structural response includes strain of longitudinal reinforcement at mid-span, and longitudinal strain on unloaded side concrete at midspan. Incident pressures were measured at $15 \mathrm{~m}, 20 \mathrm{~m}$, and $25 \mathrm{~m}$ to check if full detonation occurs. All measured data were compared with results of AUTODYN. Difference of peak reinforcement strains is $3 \%$, and one of concrete strains at surface of unloaded side is $11 \%$, showing that prepared numerical analysis can be used to estimate behavior of reinforced concrete one-way slab under explosion.
\end{abstract}

Keywords: blast loading, reinforced concrete, panel, finite element analysis.

\section{Introduction}

Explosion induces loading with high peak and short duration, causing local and global structural damage. Number of accidental explosions and terrorist attacks is increasing. However, understanding about structural behavior under explosion is still limited, especially about real size experiments. Ngo et al. [1] detonated explosive equivalent to TNT 6 ton at stand-off distance of $30 \mathrm{~m}$ and $40 \mathrm{~m}$ to observe and analyze behavior of ultra high-strength prestressed concrete panels under explosive loading. They showed 1) that prestressing is effective in improving blast resistance, 2) how Finite Element Analysis should be conducted to have reliable result. Morales-Alonso et al. [2] conducted blast test on 12 reinforced concrete slab made of normal strength concrete and high strength concrete, of which results supported validation of proposed numerical simulation model. Wang et al. $[3,4]$ tested 6 reinforced concrete slabs with different standoff-distance and TNT weight combinations to figure out relationship between slab behavior and scaled distance. Hua et al. [5] performed the test on nine specimens corresponding to three different blast intensity levels to investigate the structural response of carbon fiber sandwich panels. Li et al. [6] tested five reinforced concrete including four UHPC slabs with varying reinforcement ratios and one control NSC slab with normal reinforcement to determine their response under explosive loading conditions and the test results verified the effectiveness of UHPC slabs against blast loads.

Explosive loading is influenced by the shape, weight, detonation height, type of explosive, ambient pressure, temperature, condition of ground, detonator type and etc. Thus, it is difficult to make idealized condition like laboratory test. Moreover, the safety and large controlled area are required. Thus, limited number of real scale tests have been conducted. In this paper, one-way reinforced concrete slabs were tested in real scale. Analytical model was prepared using AUTODYN, and validated based on test results. 


\section{Experimental program}

\subsection{Specimens details}

Design compressive strength of concrete was $24 \mathrm{MPa}$. 26.6 MPa of average compressive strength and $27.708 \mathrm{MPa}$ of modulus of elasticity were measured through uni-axial compression test after 28 days of curing. $13 \mathrm{~mm}$ diameter deformed steel bars were used as longitudinal reinforcement, and $10 \mathrm{~mm}$ diameter deformed steel bar as stirrup. Yielding stress of deformed steel bar is $496.9 \mathrm{MPa}$ measured from uni-axial tension test.

Two one-way reinforced concrete slabs were prepared with $1500 \mathrm{~mm}$ width, $2350 \mathrm{~mm}$ span length, and $150 \mathrm{~mm}$ thickness. Longitudinal reinforcements were placed at both loaded and nonloaded sides with $100 \mathrm{~mm}$ spacing and $30 \mathrm{~mm}$ concrete cover. For fixed boundary condition, bolts and sleeves are used. $16 \mathrm{~mm}$ diameter sleeves were located at $115 \mathrm{~mm}$ from both edges with $200 \mathrm{~mm}$ spacing. Stirrups were placed with $100 \mathrm{~mm}$ spacing within $360 \mathrm{~mm}$ from edge, to avoid local failure at supports from stress concentrations at sleeves. Detail of slabs is shown in Fig. 1

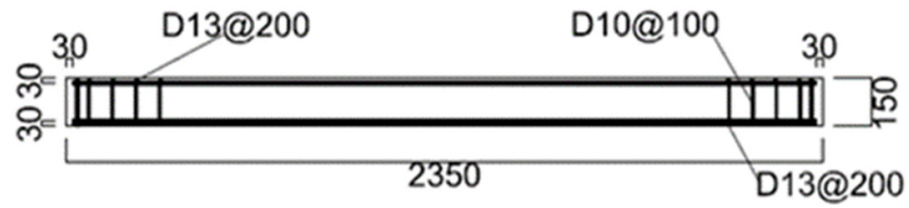

a)

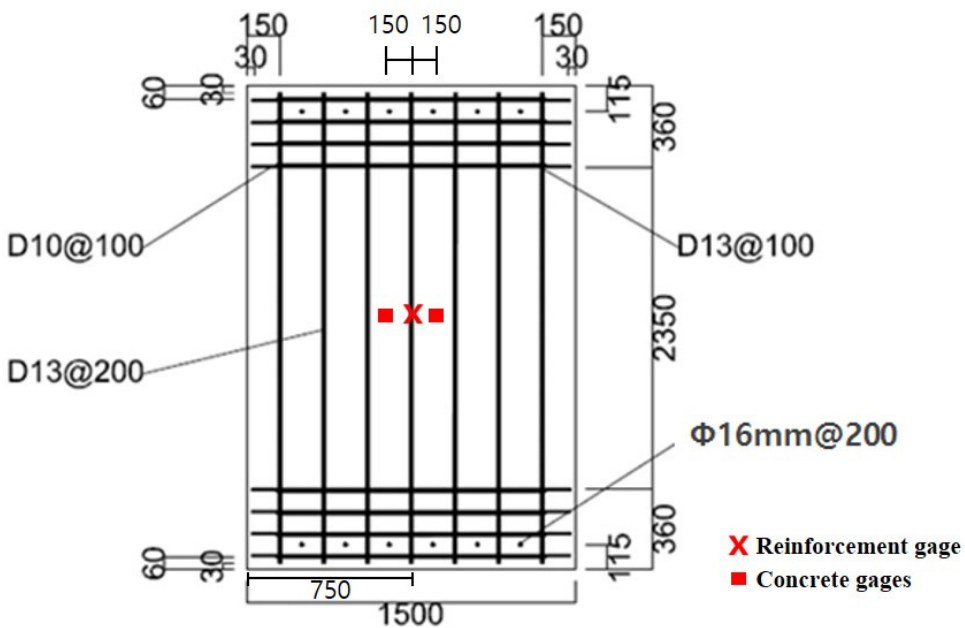

b)

Fig. 1. Details of the specimens

\subsection{Test setup}

The slab was fixed to steel frame by bolts at top and bottom, as shown in Fig. 2. Shape of frame to support slabs is shown in Fig. 3. Height of frame is $2200 \mathrm{~mm}$, and width is $1800 \mathrm{~mm}$. $4000 \mathrm{~mm} \times 4000 \mathrm{~mm} \times 200 \mathrm{~mm}$ concrete mat foundation with $35 \mathrm{MPa}$ strength is installed and connected to the steel frame to minimize the movement of frame.

In Round 1 (R1), $50 \mathrm{~kg}$ TNT was detonated at $20 \mathrm{~m}$ from slab and $1 \mathrm{~m}$ above the ground. In Round 2 (R2), $100 \mathrm{~kg}$ TNT was used. In both rounds, incident pressures were measured at $15 \mathrm{~m}$, $20 \mathrm{~m}, 25 \mathrm{~m}$ from detonation point. Strain of reinforcement was measured from gauges, which were attached to longitudinal reinforcements before curing. Gauges were placed also at the concrete surface for concrete stain. Locations of detonation point, pressure gauges and slab are shown in Fig. 4. 


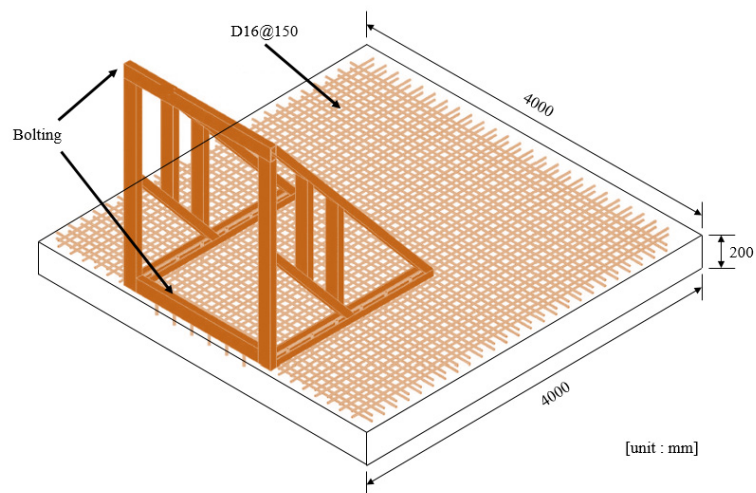

Fig. 2. Test setup

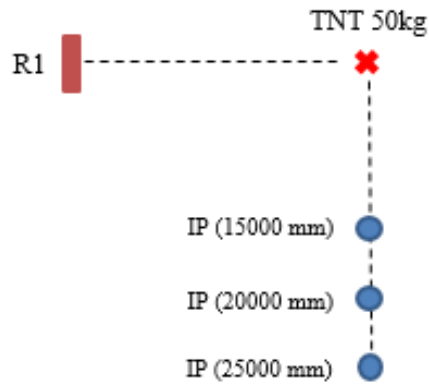

a)

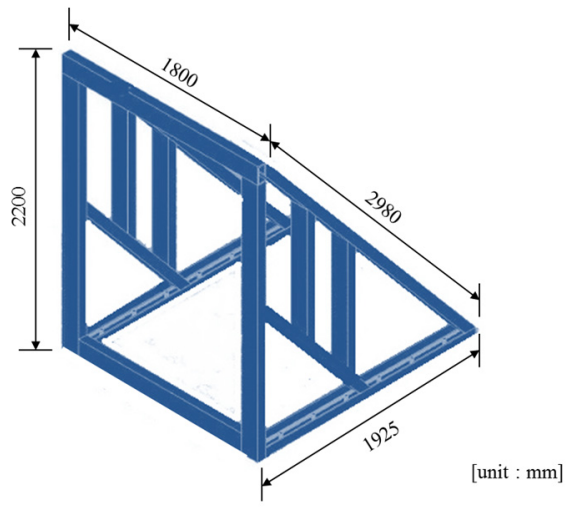

Fig. 3. Details of the steel frame

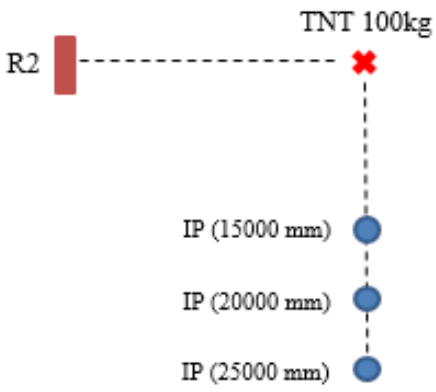

b)

Fig. 4. Location pressure sensor

\section{Numerical simulations}

In order to investigate the influence of blast loads on the concrete panel, the finite modeling was developed.

\subsection{Material model}

In order to investigate the influence of blast loads on the concrete panel, the FE modeling was developed. AUTODYN was employed in this study to model and analyze the concrete panels. To take into account the dynamic response of reinforced concrete panel under blast loads, the concrete was modeled with RHT dynamic damage concrete model [7]. This material model was developed by Riedel, Hiermayer, and Thomas [8], in which the strain hardening and the third invariant dependence were considered. An independent fracture strength surface was incorporated to allow material softening response for more accurate analysis. RHT model is expressed by three strength surface; elastic limit surface, failure surface, and residual surface. The elastic strength surface was introduced to consider material strain hardening behavior. The surface was obtained by scaling the failure surface in the radial direction. The failure surface was defined as a function of the normalized pressure, load angle, and strain rate. The residual strength surface can consider the strength of the completely crushed material. For steel reinforcement, Johnson and Cook model [9] was used. This model was used to describe the behavior of the steel reinforcement inside the concrete. Material properties of concrete and steel are described in Table 1 and Table 2, respectively.

Air was modeled as an equation of state using an ideal gas and the energy-related pressure. In this model, constant is set as 14, air density as $1.225 \mathrm{~kg} / \mathrm{m}^{3}$, initial internal energy as $206800 \mathrm{~kJ} / \mathrm{kg}$ 
Table 1. Mechanical properties for concrete model

\begin{tabular}{|c|c|}
\hline Compressive strength (MPa) & 26.6 \\
\hline Density $\left(\mathrm{kg} / \mathrm{m}^{3}\right)$ & 2,314 \\
\hline Elastic modulus $(\mathrm{MPa})$ & 27,708 \\
\hline Shear modulus $(\mathrm{GPa})$ & 16.7 \\
\hline Bulk modulus $(\mathrm{GPa})$ & 35.27 \\
\hline Poisson's ratio & 0.167 \\
\hline
\end{tabular}

Table 2. Mechanical properties for steel model

\begin{tabular}{|c|c|}
\hline Yield strength (MPa) & 496.9 \\
\hline Density $\left(\mathrm{kg} / \mathrm{m}^{3}\right)$ & 7,850 \\
\hline Elastic modulus $(\mathrm{MPa})$ & 202,804 \\
\hline Shear modulus $(\mathrm{GPa})$ & 81.8 \\
\hline Bulk modulus $(\mathrm{GPa})$ & 159 \\
\hline Poisson's ratio & 0.26 \\
\hline
\end{tabular}

\subsection{Numerical modeling}

To set sensing range of pressure gauge before test, pressure prediction was conducted using AUTODYN. The air was modelled to be $10.000 \mathrm{~mm} \times 30.000 \mathrm{~mm}$ with $25 \mathrm{~mm}$ square mesh. Axisymmetric model was prepared with $15 \mathrm{~m}, 20 \mathrm{~m}, 25 \mathrm{~m}$ distance pressure sensor (1 m height), as shown in Fig. 5. For infinite boundary condition, left and upper side of air boundary were set as flow-out condition. Charge initiation point was modelled at a right-hand corner to match the experimental setup.

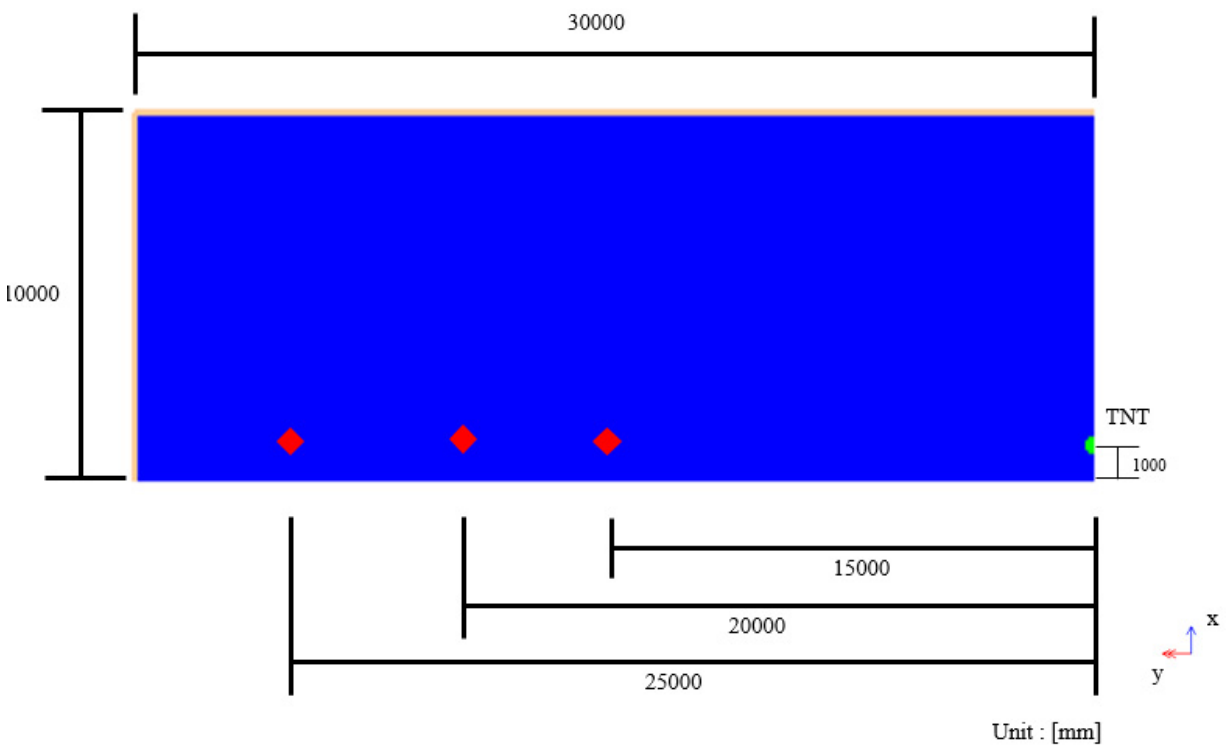

Fig. 5. 1D wedge model for pressure

To simulate and predict behavior of concrete realistically, three dimensional numerical simulation was adopted. Reinforced concrete panel was modelled using $10 \times 10 \mathrm{~mm}$ solid element, with $10 \mathrm{~mm}$ thickness as shown in Fig. 6. Each steel reinforcement was modelled explicitly using beam element. This approach allows a reasonable approximation of the bending behavior of the steel reinforcement. For fixed conditions at both ends, displacement and rotation freedoms of elements within $150 \mathrm{~mm}$ from ends were fixed. Solid element was used for concrete, beam element for reinforcement. 


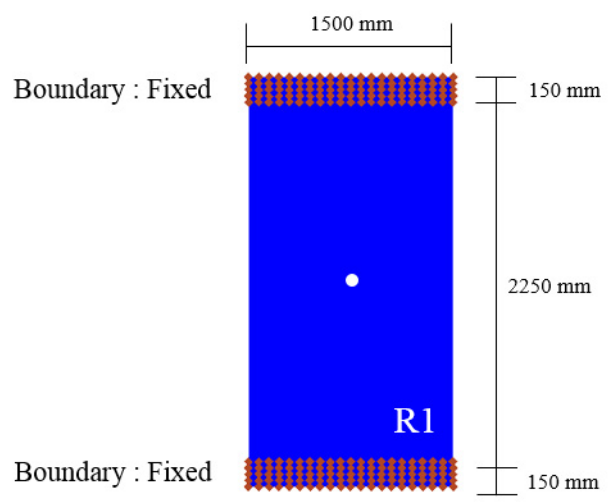

Fig. 6. Numerical modeling

\section{Comparison of numerical and experimental results}

Fig. 7 shows analytical and measured incident pressure histories of R1(TNT $50 \mathrm{~kg}$ ) and R2 (TNT $100 \mathrm{~kg}$ ), and Table 3 summarize peak incident pressures. In all cases, AUTODYN underestimates peak pressures comparing to test results. The average difference was $19 \%$ for $50 \mathrm{~kg}$ of TNT, and $25 \%$ for $100 \mathrm{~kg}$ of TNT.

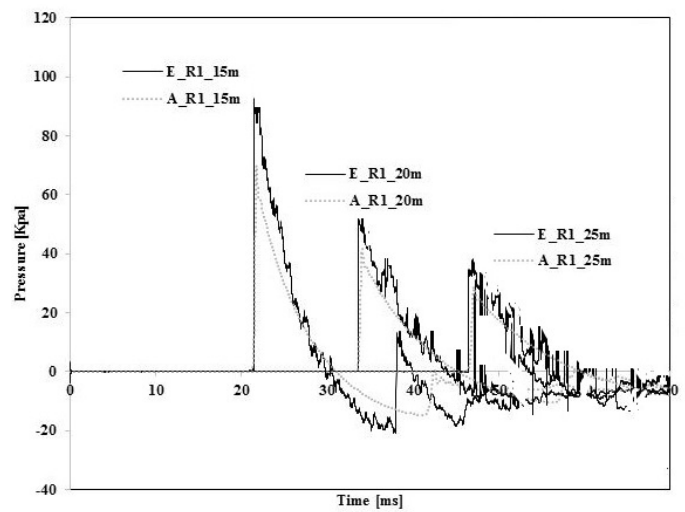

a) TNT $50 \mathrm{~kg}$

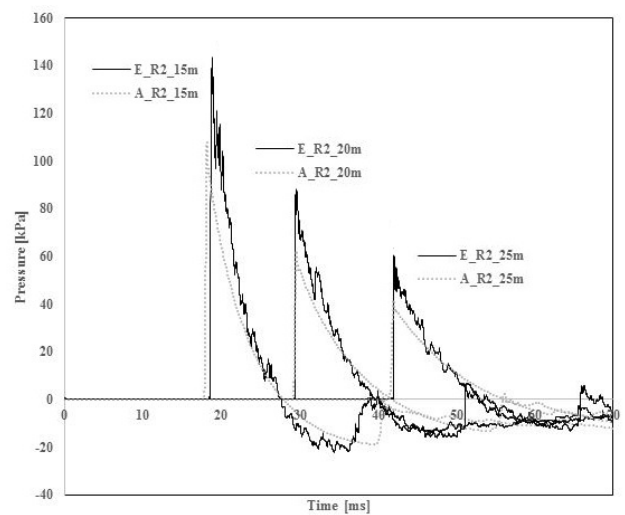

b) TNT $100 \mathrm{~kg}$

Fig. 7. Comparison of measured and predicted pressure

Table 3. Comparison between prediction and experimental results

\begin{tabular}{|c|c|c|c|c|}
\hline \multirow{2}{*}{ TNT charge mass $(\mathrm{kg})$} & \multirow{2}{*}{ Peak pressure (kPa) } & \multicolumn{3}{|c|}{ Stand-off distance } \\
\cline { 3 - 5 } & & $15 \mathrm{~m}$ & $20 \mathrm{~m}$ & $25 \mathrm{~m}$ \\
\hline \multirow{2}{*}{50} & Measured pressure & 90.45 & 52.21 & 33.62 \\
\cline { 2 - 5 } & Predicted pressure & 69.67 & 41.70 & 33.62 \\
\hline \multirow{2}{*}{100} & Measured pressure & 139.41 & 85.95 & 61.41 \\
\cline { 2 - 5 } & Predicted pressure & 111.22 & 64.00 & 42.81 \\
\hline
\end{tabular}

In Round 1, any reliable data was not collected, caused by unestablished line connection during concreter curing. Fig. 8 shows reinforced steel strains from AUTODYN and test in R2 (TNT $100 \mathrm{~kg}$ ). Maximum strain from test is $305 \times 10^{6}$ and one from AUTODYN is $314 \times 10^{6}$ showing $3 \%$ difference.

Fig. 9 shows concrete stain measured on unloaded side at midspan in R2 (TNT $100 \mathrm{~kg}$ ) from test and AUTODYN. The strain gauges were attached to the longitudinal reinforcing bars and surface of concrete as shown Fig. 1. Analytical results (A_R2_C1 and A_R2_C2) do not show meaningful difference in strain histories. However, $30 \overline{\%}$ of maximum strain difference is 
observed in test results (E_R2_C1 and E_R2_C1), caused by the direction of the wind. Stiff descending strain after maximum value in test results comparing to analytical ones is caused by detachment of strain gauges after peak extension. The average maximum concrete strain from test is 0.00218 , one from AUTODYN is 0.0012 , showing $11 \%$ difference.

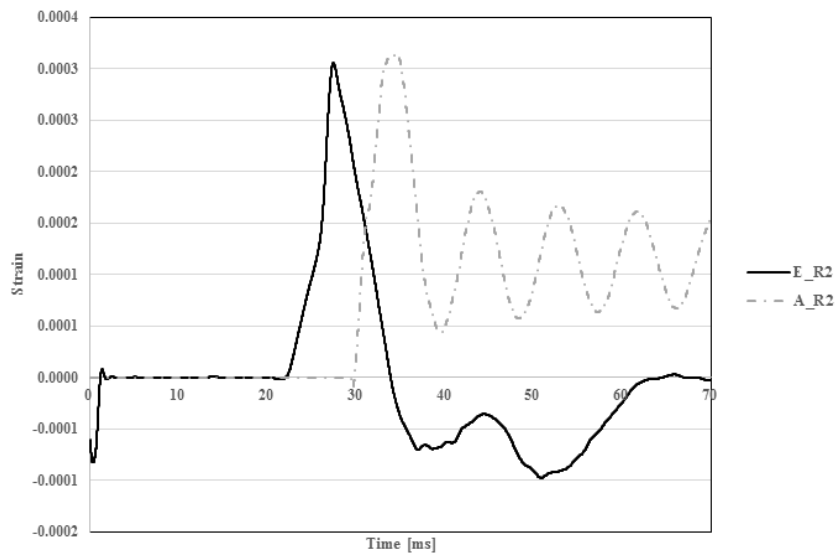

Fig. 8. Comparison of measured and predicted strain for longitudinal reinforcement (TNT $100 \mathrm{~kg}$ )

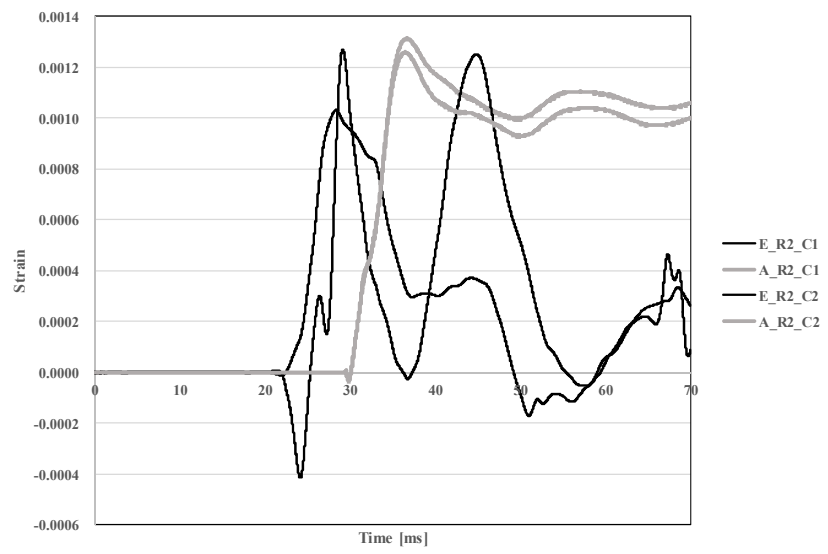

Fig. 9. Comparison of measured and predicted strain for concrete (TNT $100 \mathrm{~kg}$ )

\section{Conclusions}

In this paper, behavior of one-way reinforce concrete slab under explosive loading was tested and analyzed. Two tests were conducted with $50 \mathrm{~kg}$ and $100 \mathrm{~kg}$ TNT. Incident pressures were measured as $19 \%$ greater, and $25 \%$ greater than numerical results in $50 \mathrm{~kg}$ and $100 \mathrm{~kg}$ TNT detonation, respectively. This difference can be caused by ground condition, TNT shape, sensor direction, etc.

Although measurement of deflection failed due to small deflection and ground shock, Maximum strain in reinforcement shows $3 \%$ difference between test and analysis, and concrete strain at surface of unloaded side shows $11 \%$ difference. This represents that numerical approach can simulate behavior of reinforced concrete slab under explosion with reasonable accuracy.

\section{Acknowledgements}

This work was supported by the Agency for Defense Development, Korea (2014-1294) and the National Research Foundation of Korea (NRF) Grant funded by the Korea Government (MSIP) 


\section{References}

[1] Ngo T., Mendis P., Krauthammer T. Behavior of ultra high-strength prestressed concrete panels subjected to blast loading. Journal of Structural Engineering, Vol. 133, Issue 11, 2007, p. 1582-1590.

[2] Morales-Alonso G., Cendon D. A., Galvez F., Erice B., Sanchez-Galvez V. Blast response analysis of reinforced concrete slabs: Experimental procedure and numerical simulation. Journal of Applied Mechanics, Vol. 78, Issue 5, 2011, p. 1-12.

[3] Wang W., Zhang D., Lu F., Wang S. C., Tang F. Experimental study on scaling the explosion resistance of a one-way square reinforced concrete slab under a close-in blast loading. Journal of Impact Engineering, Vol. 49, 2012, p. 158-164.

[4] Wang W., Zhang D., Lu F., Wang S. C., Tang F. Experimental study and numerical simulation of the damage mode of a square reinforced concrete slab under close-in explosion. Engineering Failure Analysis, Vol. 27, 2013, p. 41-51.

[5] Hua Y., Akula P. K., Gu L. Experimental and numerical investigation of carbon fiber sandwich panels subjected to blast loading. Composites Part B: Engineering, Vol. 56, 2014, p. 456-463.

[6] Li J., Wu C., Hao H. An experimental and numerical study of reinforced ultra-high performance concrete slabs under blast loads. Materials and Design, Vol. 82, 2015, p. 64-76.

[7] Autodyn. Theory Manual. Century Dynamics Ltd, Horsham, UK, 2005.

[8] Riedel W., Thoma K., Hiermaier S. Numerical analysis using a new macroscopic concrete model for hydrocodes. Proceedings of 9th International Symposium on Interaction of the Effects of Munitions with Structures, 1999, p. 315-322.

[9] Hohnson G. R., Cook W. H. A constitutive model and data for metals subjected to large strains, high strain rates and high temperatures. Proceedings of the Seventh International Symposium on Ballistics, 1983, p. 541-548.

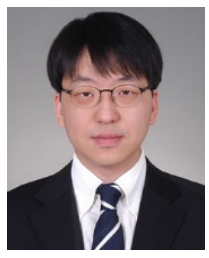

Jong Yil Park received Ph.D. in civil engineering from Pennsylvania State University, PA, USA in 2006. Now he works at Seoul National University of Science and Technology. His current research interests include disaster management and construction safety.

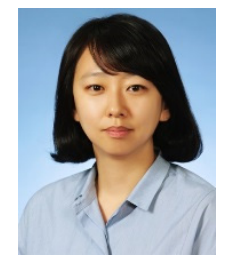

Min Sook Kim is a research fellow in the Department of Architectural Engineering at Kyung Hee University. She received her Ph.D. from Kyung Hee University, Korea. Her research interests include the behavior of reinforced concrete members and the behavior of reinforced concrete members developing analytical models of concrete structures.

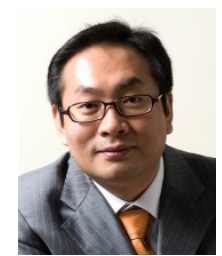

Young Hak Lee is a Professor in the Department of Architectural Engineering at Kyung Hee University. He received his Ph.D. from the Pennsylvania State University, PA, USA. His research interests include the dynamic behavior of reinforced concrete members under blast loads and developing analytical models of concrete structures. 